\title{
Methane emissions from ruminant livestock; are they important and can we reduce them?
}

\author{
H. CLARK \\ AgResearch Grasslands, Private Bag 11-008, Palmerston North, New Zealand \\ harry.clark@agresearch.co.nz
}

\begin{abstract}
Globally methane emissions from ruminant livestock account for $5-6 \%$ of total anthropogenic carbon dioxide equivalent emissions. In New Zealand, methane emissions from ruminants comprise $31.5 \%$ of our total emissions putting us in a unique position within the developed world. Reducing methane emissions from ruminant livestock is technically challenging and has to be achieved against a rising demand for animal products. There is currently no price on emissions meaning that there is little incentive for farmers to adopt mitigation practices unless these practices are profitable in their own right. In the short term the mitigation opportunities already identified by researchers have limited applicability for grazing ruminants or they involve actions (e.g. reducing animal numbers) that may adversely affect profitability. In the medium and longer term direct modification of rumen microbial processes (e.g. vaccination against methanogens) and the breeding of 'low' methane producing animals offer promise for universal, cost effective solutions.
\end{abstract}

Keywords: methane, mitigation, ruminants

\section{Introduction}

Methane $\left(\mathrm{CH}_{4}\right)$ and nitrous oxide $\left(\mathrm{N}_{2} \mathrm{O}\right)$ are the principle greenhouse gases ( $\mathrm{GHG}$ ) arising from the farming of ruminant animals although small quantities of $\mathrm{CO}_{2}$ are emitted from on-farm activities such as transport and heating. In their seminal report on the environmental impacts of livestock production, Steinfeld et al. (2006) estimated that approximately $14 \%$ of all carbon dioxide equivalent $\left(\mathrm{CO}_{2} \mathrm{e}\right)$ GHG emissions emanated from the livestock sector, a contribution similar to that of transport. However, this included emission from all sources and all sectors not just $\mathrm{CH}_{4}$ from ruminants. Estimating the contribution of $\mathrm{CH}_{4}$ emissions from ruminant livestock to total agricultural $\mathrm{GHG}$ emissions is problematic due to the diversity of sources and a lack of data.

\section{Quantifying $\mathrm{CH}_{4}$ emissions from ruminant animals}

The main source of $\mathrm{CH}_{4}$ emissions from ruminants is enteric methane arising as a by-product of the fermentation of feed in the rumen and, to a lesser extent, the large intestine. The rumen contains a large and diverse population of microorganisms which break down ingested feed to produce volatile fatty acids (VFA's), $\mathrm{CO}_{2}$ and $\mathrm{CH}_{4}$. The VFA's produced in the rumen are absorbed and used as an energy source, but most of the $\mathrm{CO}_{2}$ and $\mathrm{CH}_{4}$ are removed from the rumen by eructation. Typically more than $80 \%$ of the $\mathrm{CH}_{4}$ is produced in the rumen and the rest in the lower digestive tract (Immig 1996; Murray et al. 1976). The majority of the $\mathrm{CH}_{4}$ produced $(>95 \%)$ is released via the mouth with only a small proportion $(<5 \%)$ released via the flatus (Murray et al. 1976). Typically $3.5-7.5 \%$ of the gross energy consumed is lost as $\mathrm{CH}_{4}\left(\mathrm{O}^{\prime} \mathrm{Hara}\right.$ et al. 2003). A second source of $\mathrm{CH}_{4}$ is that arising from voided faecal material. Emissions from this source vary considerably; in grazing animals, where faecal material is deposited directly onto pastures, only small amounts of $\mathrm{CH}_{4}$ arise from this source but in situations where manures are stored for prolonged periods in anaerobic conditions relatively large quantities of $\mathrm{CH}_{4}$ can be emitted.

Steinfeld et al. (2006), using a mix of Intergovernmental Panel on Climate Change (IPCC) Tier 1 and Tier 2 approaches, estimated global enteric emissions from ruminant livestock to be of the order of $84 \mathrm{Mt}$ tyear. Clark et al. (2005) also adopted an IPCC Tier 2 type approach and arrived at a lower estimate of $70.4 \mathrm{M} \mathrm{t} /$ year. These two values typify the range of values found in the literature (IPCC 2001) for global enteric $\mathrm{CH}_{4}$ production. Steinfeld et al. (2006), again using a mix of Tier 1 and Tier 2 approaches, estimated global annual $\mathrm{CH}_{4}$ emissions from manure management to be in the order of $8.2 \mathrm{M} \mathrm{t} / \mathrm{year}$, a figure that is much higher than previous estimates (e.g. US-EPA 2005). Steinfeld et al. (2006) present a figure for all anthropogenic $\mathrm{CH}_{4}$ emissions of $5.9 \mathrm{G} \mathrm{t} /$ year $\mathrm{CO}_{2} \mathrm{e}$ which suggests that ruminant animals emit between 25 and $33 \%$ of the all anthropogenic $\mathrm{CH}_{4}$ emissions.

Total anthropogenic $\mathrm{GHG} \mathrm{CO}_{2} \mathrm{e}$ emissions are estimated to be in the order of $33 \mathrm{G} \mathrm{t} / \mathrm{year}$ (Steinfeld et al. 2006) indicating that $\mathrm{CH}_{4}$ emissions from ruminant livestock account for between 5 and $6 \%$ of global anthropogenic emissions. However, this figure varies dramatically between countries. For many developed countries the figure will typically be $3 \%$ or less but for some developing countries, for example Uruguay, Brazil and Argentina the figure is more than 25\% 
(UNFCC 2009). New Zealand is unique among the developed countries since the latest estimates are that $\mathrm{CH}_{4}$ emissions from ruminants account for $31.5 \%$ of total estimated $\mathrm{CO}_{2}$ e emissions (MfE 2009).

\section{Mitigating GHG emissions from ruminant animals}

Successful mitigation of ruminant GHG emissions is challenging technically but is made even more difficult because of the rising demand for milk and meat (Steinfeld et al. 2006). A further challenge is that even if technical solutions are available these solutions also need to be practical to implement and economically viable if they are to be adopted by farmers. This latter point is highly important since at present there are limited incentives for the adoption of mitigation technologies because of the general lack of a price signal; emission trading schemes are in place in a number of countries but so far none of these schemes include agriculture. A further point is that reductions in emissions need to be viewed holistically; reducing on-farm enteric $\mathrm{CH}_{4}$ emissions by feeding more grain brings no net benefits if this simply increases emissions of another gas at a different part of the value chain.

\section{Mitigating enteric $\mathrm{CH}_{4}$ emissions}

This section will concentrate only on reducing enteric $\mathrm{CH}_{4}$ production, the main route of $\mathrm{CH}_{4}$ production in most ruminant production systems (Table 1) and will not consider emissions from animal manures.

\section{Short term opportunities}

Reducing animal numbers is an obvious way to reduce emissions, although one that may not be acceptable to many farmers. It has been happening in some countries (e.g. European Union, USA) but overall ruminant populations have increased slightly over the last 10 years (FAO 2009). Reducing animal numbers may also not be enough by itself since an increase in productivity per animal (and hence $\mathrm{CH}_{4}$ emissions per head) may cancel out any benefits from reduced animal numbers. Increasing productivity per animal will reduce emissions per unit of product due to a smaller proportion of the feed consumed being needed for maintenance. However, total emissions will be little changed if the total feed consumed remains the same and/or the amount of product produced increases (Clark et al. 2005). There are opportunities to reduce $\mathrm{CH}_{4}$ emissions by amending ruminant diets. Increasing the proportion of grain in the diet can reduce $\mathrm{CH}_{4}$, total farm GHG emissions and increase profitability (Lovett et al. 2006) although a careful assessment of individual circumstances is needed before this can be recommended in all circumstances. Adding lipids to the diet also shows promise (Beauchemin et al. 2008). However, both of these technologies are of limited value for those situations in which animals graze outdoors for most of their lives and consume forage only diets. Changing the type of forage offered (e.g. legumes, condensed tannins) has also been shown to influence enteric $\mathrm{CH}_{4}$ emissions (Waghorn et al. 2002), however, any alternative species have to be as good agronomically as the species currently utilised and this may well limit the use of these alternative species in practice. The ionophore, monensin, has been found to reduce enteric $\mathrm{CH}_{4}$ emissions in some circumstances (Beauchemin et al. 2008) and, since it also has productivity and health benefits, has attracted widespread scientific attention. However, the effects are variable and may not be long lasting. These compounds are also classed as antibiotics and their use is unacceptable in some locations. Other compounds with claimed efficacy for reducing enteric $\mathrm{CH}_{4}$ are available which can broadly be classed as rumen modifying agents; these include yeasts, condensed tannin extracts, probiotics and enzymebased feed additives. Although available commercially the data supporting reductions in emissions are sparse and further work is needed before any of these products can be recommended as mitigation agents.

\section{Medium term opportunities}

Although rumen modifiers are available now a more realistic appraisal is that they hold promise for the future not the present since these products have been developed with productivity increases in mind rather than $\mathrm{CH}_{4}$ reduction. However, this could change if there is a price on $\mathrm{CH}_{4}$ which would generate co-benefits for the commercial manufacturers of such products. Possible approaches include plant extracts such as allicin, bacteriocins and improved yeast products (Macallister \& Newbold 2008; Newbold \& Rode 2006). Breeding for plant traits that will reduce enteric $\mathrm{CH}_{4}$ emissions is also a medium term possibility. The best example of this so far is the breeding of so called 'high sugar' grasses (Abberton et al. 2008). Although they may have more of an effect on $\mathrm{N}_{2} \mathrm{O}$ emissions on theoretical grounds at least, they may also reduce $\mathrm{CH}_{4}$ emissions (Abberton et al. 2008). A major challenge for animal scientists is to clearly identify the specific plant chemical characteristics that influence enteric $\mathrm{CH}_{4}$ formation; this is not a simple task since evidence so far suggests that on forage- based diets it is difficult to identify from proximate analysis which components of the diet have a strong influence on $\mathrm{CH}_{4}$ emissions (Hammond et al. 2009).

\section{Long term opportunities}

The targeted manipulation of the rumen ecosystem 
Table 1 A summary of the main routes for reducing enteric $\mathrm{CH}_{4}$ emissions from ruminant livestock categorised according to availability. Short (available now), medium (commercially available in the next 10 years), long (not likely to be commercially available within the next 10 years).

\begin{tabular}{lll}
\hline Short & Medium & Long \\
\hline Reduce animal numbers & Rumen modifiers & Targeted manipulation of rumen ecosystem \\
$\begin{array}{l}\text { Manipulate diet } \\
\text { Increase productivity per animal }\end{array}$ & Plants with low $\mathrm{CH}_{4}$ yield & Breed animals with low $\mathrm{CH}_{4}$ yield \\
Rumen modifiers & & \\
\hline
\end{tabular}

provides perhaps the best hope for mitigating enteric $\mathrm{CH}_{4}$ emissions and perhaps the biggest challenge. Developing vaccines which stimulate ruminants to produce antibodies against their rumen methanogens may be feasible in principle (Wright et al. 2004) but the successful development of a vaccine is still a long way off. Technical challenges include developing a vaccine that has a substantive effect on emissions, has broad spectrum activity and long term efficacy. Phage therapy is also another possible route (Mcallister \& Newbold 2008), as is the development of a new generation of 'designer' inhibitors based on knowledge of the genome of rumen methanogens. Breeding animals which emit less methane is also a possibility. Two approaches are currently being taken; breeding animals with improved feed conversion efficiency (Hegarty \& Allcock 2006) and breeding animals with low emissions per unit of feed consumed (Pinares-Patino 2008). The first approach is attractive since the selected animals will have high productivity combined with lower feed intake. This means lower $\mathrm{CH}_{4}$ / unit of product, lower total $\mathrm{CH}_{4}$ (although this may be offset by increased stocking rates) and reduced feed costs per animal. Breeding animals with low emissions per unit feed intake will guarantee a reduction in total $\mathrm{CH}_{4}$ emissions but for successful adoption productivity traits will have to be unaffected. Work so far has identified that there are differences between individual animals in emissions per unit of feed but so far these differences have proved to be transitory rather than permanent (Pinares-Patino 2008).

\section{Summary}

Developing technologies that reduce GHG emissions from ruminant animals presents a stern challenge to the scientific community. The need to reduce emissions while leaving productivity and profitability unchanged, the diversity of production systems, the lack of a price signal and the biological complexity of the processes controlling emissions suggest that simple universal solutions are unlikely to be developed and, importantly, adopted in the short term. It is more likely that a suite of technologies will emerge over time which will provide mitigation tools and technologies appropriate to the range of production systems found in practice. The impacts of climate change are assessed over decades and successfully reducing total GHG emissions from ruminant animals globally when the demand for animal protein is increasing has to be assessed using a similar timescale.

\section{REFERENCES}

Abberton, M.T.; Marshall A.H.; Humphreys, M.W.; Macduff, J.H.; Collins, R.P.; Marley, C.L. 2008. Genetic improvement of forage species to reduce the environmental impact of temperate livestock grazing systems. Advances in Agronomy 98: 311-355.

Alford, A.R.; Hegarty, R.S.; Parnell, P.F.; Cacho, O.J.; Herd, R.M.; Griffith, G.R. 2006. The impact of breeding to reduce residual feed intake on enteric methane emissions from the Australian beef industry. Australian Journal of Experimental Agriculture 46: 813-820.

Beauchemin, K.A.; Kreuzer, M.; O'Mara, F.; McAllister, T.A. 2008. Nutritional management for enteric methane abatement: a review. Australian Journal of Experimental Agriculture 48: 21-27.

Clark, H.; Pinares-Patino, C.; deKlein, C. 2005. Methane and nitrous oxide emissions from grazed grasslands. pp. 279-294. In: Grassland: a global resource. Ed. McGilloway, D.A. Wageningen Academic Publishers, Netherlands.

FAO, 2009 http://www.fao.org/ag/aga/glipha/index.jsp Hammond, K.J.; Muetzel, S.; Waghorn, G.C.; PinaresPatino, C.S.; Burke, J.L.; Hoskin, S.O. 2009. The variation in methane emissions from sheep and cattle is not explained by the chemical composition of ryegrass. Proceedings of the New Zealand Society of Animal Production 69: 174-178.

Immig, I. 1996. The rumen and hindgut as source of ruminant methanogenesis. Environmental monitoring and assessment 42: 57-72.

IPCC, 2001. IPCC third assessment report: climate change 2001: the scientific basis. Contribution of Working Group I to the Third Assessment Report of the Intergovernmental Panel on Climate Change (IPCC). Eds. Houghton, J.T.; Ding, Y.; Griggs, D.J.; Noguer, M.; van der Linden, P.J.; Xiaosu, D. Cambridge University Press, UK. 881pp. 
Lovett, D.K.; Shalloo, L.; Dillon, P.; O’Mara, F.P. 2006. A systems approach to quantify greenhouse gas fluxes from pastoral dairy production as affected by management regime. Agricultural Systems 88: 156-179.

Ministry for the Environment, 2009. New Zealand's Greenhouse Gas Inventory 1990-2007. An overview. www.mfe.govt.nz

Macallister, T.A.; Newbold, C.J. 2008. Redirecting rumen fermentation to reduce methanogenesis Australian Journal of Experimental Agriculture 48: 7-13.

Murray, R.M.; Bryant, A.M.; Leng, R.A. 1976. Rates of production of methane in the rumen and large intestine of sheep. British Journal of Nutrition 36: 1-14.

Newbold, C.J.; Rode, L.M. 2006. Dietary additives to control methanogenesis in the rumen. In 'Greenhouse gases and animal agriculture: an update'. Elsevier International Congress Series 1293. pp. 138-147.

O'Hara, P.; Freney, J.; Ulyatt, M. 2003. Abatement of agricultural non-carbon dioxide greenhouse gas emissions. A study of research requirements. A report prepared for the Ministry of Agriculture and Forestry on behalf of the Convenor, Ministerial Group on Climate Change, the Minister of Agriculture, and the Primary Industries Council. May 2003, New Zealand Ministry of Agriculture and Forestry, Wellington. 171 pp. www.govt.nz/publications

Pinares-Patino, C.S.; Waghorn, G.C.; Machmuller,
A.; Vlaming, B.; Molano, G.; Cavanagh, A.; Clark, H. 2008. Variation in methane emission - effect of feeding and digestive physiology in non-lactating dairy cows. Canadian Journal of Animal Science 88: 309-320.

Steinfeld, H.; Gerber, P.; Wassenaar, T.; Castel, V.; Rosales, M.; de Haan, C. 2006. Livestock's Long Shadow. FAO 2006.

US-EPA, 2005. Global warming - Methane. US Environmental Protection Agency. http://www. epa.gov/methane/

UNFCC, 2009 http://unfccc.int/di/DetailedByParty/ Event.do?event $=g_{0}$

Waghorn, G.C.; Tavendale, M.H.; Woodfield, D.R. 2002. Methanogenesis from forages fed to sheep. Proceedings of the New Zealand Grassland Association 64: 167-171.

Wright, A.D.G.; Kennedy, P.; O’Neill, C.J.; Toovey, A.F.; Popovski, S.; Rea, S.M.; Pimm C.L.; Klein, L. 2004. Reducing methane emission in sheep by immunization against rumen methanogens. Vaccine 22: 3976-3985. 